\title{
KARAKTER VISUAL KAWASAN WISATA BATIK TULIS LASEM KABUPATEN REMBANG
}

\author{
Mutiawati Mandaka $^{\text {a1) }}$, Adi Sasmito ${ }^{\text {b2) }}$, Taufiq Rizza Nuzuluddin ${ }^{\text {c3) }}$ \\ a,b,c Program Studi S1 Arsitektur Fakultas Teknik Universitas Pandanaran Semarang \\ Jl. Banjarsari Barat No 1 Pedalangan, Banyumanik, Semarang \\ Email ${ }^{1}$ : mutia.mandaka@unpand.ac.id \\ Email2: adisas@unpand.ac.id \\ Email ${ }^{3}$ : taufiqrizza@unpand.ac.id
}

\begin{abstract}
ABSTRAK
Penelitian Karakter Visual Kawasan Wisata Batik Tulis Lasem Kabupaten Rembang bertujuan mencari komponen-komponen yang membentuk dan mempengaruhi karakter visual area kawasan wisata Batik Tulis Lasem dan untuk menemukan kaitan visual antara karakter visual beberapa area Batik Tulis Lasem yang ada di Kawasan Wisata Batik Lasem Kabupaten Rembang. Ada beberapa hal yang dikaji untuk melihat karakter visual kawasan yaitu komponen karakter fisik arsitektur yang meliputi: Karakter Bangunan: fasade Bangunan, skala ketinggian bangunan, langgam/gaya, material, tekstur, warna; Karakter Lingkungan: path, edge, node, landmark. Dan kemudian untuk melihat karakter visual kawasan juga perlu mengkaji tentang karakter non fisik yang melatarbelakangi pembentukan fisik. Berdasarkan hasil penelitian dan pembahasan yang telah dilakukan mendapatkan kesimpulan bahwa karakter visual area Desa Wisata Batik Lasem pada Desa Babagan terlihat paling menonjol diantara tiga Desa lainnya. Permukiman Cina pada Desa Babagan terlihat sangat mendominasi area wisata Batik Tulis ini. Dan permukiman penduduk asli lainnya tersebar di tiga desa lainnya yaitu Karasgede, Karaskepoh dan Tuyuhan. Karakter visual pada desa wisata Batik Tulis ini terbentuk dari karakter fisik sebagai komponen utama dan ditunjang oleh keberadaan karakter non fisik sebagai komponen penunjang, dengan memperhatikan sejarah perkembangan Lasem. Karakter pada sequence area rumah mengalami pergeseran menyesuaikan dengan lokasi masing-masing desa. Pada Desa Babagan, karakter rumah tinggal yang bertahan ini merupakan karakter asli yang menjadi identitas kawasan. Dari hal tersebut terlihat bahwa area permukiman Kawasan Desa Wisata Batik Lasem mempunyai karakter visual yang relatif bertahan dan perlu dijaga keberadaannya, sehingga penting untuk menemukan jenis karakter visualnya agar dapat ditentukan cara menjaganya dan agar dapat memberikan masukan sebagai bahan pertimbangan aspek atau komponen yang perlu dipertahankan dan komponen yang harus dikembangkan dalam revitalisasi kawasan Desa Wisata Kabupaten Rembang.
\end{abstract}

Kata Kunci: Karakter Visual, Rumah Tinggal, Desa Wisata Batik Lasem

\begin{abstract}
Research on Visual Character of Lasem Batik Tulis Tourism Area Rembang Regency aims to look for components that shape and influence the visual character of the Lasem Batik Tulis tourist area and to find a visual link between the visual characters of some Batik Tulis Lasem areas in the Lasem Batik Tourism Area of Rembang Regency. There are several things that are studied to see the visual character of the area, namely the physical character component of architecture which includes: Building Character: Building facade, building height scale, style / style, material, texture, color; Environmental Character: path, edge, node, landmark. And then to see the visual character of the area also need to study the non-physical character behind the physical formation. Based on the results of the research and discussion that has been carried out, it can be concluded that the visual character of this Batik Tulis tourism village is formed from physical character as the main component and is supported by the presence of non-physical characters as a supporting component, taking into account the history of Lasem development. In Babagan Village, the character of the surviving dwelling house is an original character that is a regional identity so it is important to find the type of visual character so that it can be determined how to maintain it and can provide input as a consideration for aspects or components that need to be maintained and components that must be developed in the area revitalization Tourism Village of Rembang Regency.
\end{abstract}

Keyword: Visual character, surviving dwelling house, Lasem Batik Tulis Tourism Area Rembang Regency 


\section{PENDAHULUAN}

Desa Wisata yang terletak di Kecamatan Lasem Kabupaten Rembang merupakan bagian dari sistem pengelolaan hasil karya batik tulis yang berasal dari warisan nenek moyang yang memiliki nilai sejarah dan seni tinggi yang diturunkan secara turun temurun. Hasil produksi dari batik Lasem mempunyai kekhasan tersendiri. Keadaan saat ini menunjukkan bahwa kesan atas produk (product image) terhadap batik tulis Lasem masih cukup kuat, khususnya dikalangan kolektor batik kuno dan konsumen lainnya.

Sejarah batik tulis Lasem yang kuat serta mempunyai ciri khas tersendiri membuat batik tulis Lasem bagi sekalangan orang dirasa lebih istimewa dibanding batik-batik sejenis. Cara pembuatannya yang masih menggunakan proses tradisional juga membuat batik tulis Lasem menjadi lebih berkelas, dan mempunyai daya saing yang cukup tinggi di pasar perbatikan.

Kekhasan ini membuat suatu produksi hasil Batik Tulis sudah dipasarkan berbagai daerah dan bahkan di luar Jawa. Lokasi sentra perajin Batik Tulis kabupaten Rembang seluruhnya ada 59 perajin tetapi semuanya menyebar berada di lokasi Kecamatan Lasem dan kecamatan Pancur. Kecamatan Lasem menyebar di Desa Selopuro, Desa Gedongmulyo, Desa Karangturi, Desa Sumbergirang, Desa Soditan dan Desa Babagan. Kecamatan Pancur di Desa Jeruk, Desa Pohlandak dan Desa Karaskepoh.

Batik tulis Lasem merupakan salah satu produk unggulan Kabupaten Rembang yang berasal dari warisan nenek moyang yang memiliki nilai sejarah dan seni tinggi yang diturunkan secara turun temurun. Potensi lokasi kawasan Desa Wisata Batik Lasem terdapat kawasan Pecinan dan masih mempunyai nilai arsitektur asli, serta bangunan kuno lainnya seperti Masjid Kuno di tepi jalan raya.

Klenteng, serta lokasinya terbelah oleh sungai Babagan. Lokasi Kawasan sekarang ini sudah ada Show Room Batik di tepi jalan raya serta sudah ada petunjuk lokasi menuju sentra perajin batik. Kawasan desa wisata perlu adanya penggalian potensi yang mendukung kawasan, serta jalur yang jelas. Disamping itu juga untuk melestarikan, mempromosikan dan mengembangkan batik tulis Lasem, Desa Babagan, dan Karasgede merupakan salah satu sentra perajin batik tulis Lasem.

Dalam upaya pengaturan dan penataan kawasan Batik, peneliti akan mencari faktorfaktor yang mempengaruhi karakter visual pada beberapa bangunan di kawasan batik, agar fungsi kawasannya terjaga, yaitu sebagai kawasan desa wisata batik dan pengembangan pariwisata. Pengembangan pariwisata di Kawasan desa Wisata Batik agar kegiatan kawasan dapat saling mendukung satu sama lain. Penelitian di kawasan ini adalah upaya pemanfaatan potensi yang ada, serta membuat kekhasan desa wisata agar embrio aktifitas pariwisata bisa tumbuh dan berkembang di kecamatan Lasem.

Area Kawasan Wisata Batik Lasem mempunyai karakter visual yang relatif bertahan dan perlu dijaga keberadaannya, sehingga penting untuk menemukan jenis karakter visualnya agar dapat ditentukan cara menjaganya. Karakter visual area kawasan kecamatan Lasem merupakan studi untuk mendapatkan gambaran tentang karakter visual di area-area kawasan Wisata Batik Lasem yang terbentuk dan dipengaruhi oleh unsur-unsur fisik yang masing-masing mempunyai fungsi tertentu dan unsur-unsur tersebut satu sama lain saling berpengaruh.

\section{Rumusan Permasalahan}

Dari uraian tersebut di atas, dapat dirumuskan permasalahan penelitian sebagai berikut:

1. Apa saja komponen-komponen yang membentuk dan mempengaruhi karakter visual area Kawasan Batik Lasem di Rembang?

2. Adakah kaitan visual antara karakter visual beberapa area wilayah desa yang ada di Kawasan Wisata Batik Lasem di Rembang?

Ruang lingkup penelitian yang menjadi substansi dalam studi ini adalah komponen karakter bangunan dan karakter lingkungan yang membentuk dan mempengaruhi karakter visual kawasan. Adapun kawasan desa wisata Batik ini meliputi: batas wilayah kampung batik adalah Desa Babagan, Desa Karanggede, Desa Karaskepoh (Pancur), sampai dengan Desa Tuyuhan. 


\section{METODOLOGI PENELITIAN \\ Pendekatan Penelitian}

Pada penelitian ini metode yang dipergunakan adalah pendekatan rasionalistik dengan paradigma kualitatif. Metodologi penelitian kualitatif rasionalistik ini dimulai dari pendekatan holistik berupa grand concept yang dijabarkan melalui teori substantive, obyek diteliti dengan tanpa dilepaskan dari konteksnya dalam fokus/aksentuasi tertentu dan hasil penelitiannya ditempatkan kembali pada grand conceptnya (Muhadjir, 1996).

\section{Komponen Penelitian}

1. Komponen utama berupa karakter fisik lingkungan desa wisata Batik Lasem kabupaten Rembang, yang membentuk dan mempengaruhi karakter visual kawasan, sesuai dengan teori Cullen (1961), terdiri dari: karakter bangunan, karakter lingkungan dan integrasi karakter bangunan dan lingkungan.

2. Komponen penunjang berupa karakter non fisik kawasan desa wisata Batik Lasem, terutama karakteristik sosial budaya yang menunjang terbentuknya karakter visual lingkungan pertokoan Batik.
Alat Penelitian
1. Peta
2. Kamera
3. Kertas dan alat gambar
4. Meteran

Alat yang digunakan untuk pengumpulan data mencakup antara lain sebagai berikut:

\section{Teknik Pengumpulan Sampel}

Teknik yang digunakan dalam penentuan sampel adalah purpositive sampling yaitu sampling bertujuan atau tidak acak. Karakteristik sampel ini adalah :

1. Desain sampel yang sementara sifatnya, spesifikasi sampel tidak dirancang apriori.

2. Unit-unit diseleksi secara berkelanjutan sesuai dengan informasi yang diperoleh di lapangan.

3. Penyesuaian dan pemfokusan sampel secara berkelanjutan

Penentuan sampel ini dibagi dalam beberapa area pengamatan sesuai dengan analisa bahwa di Desa Wisata Lasem ini terdapat 4 area pembagian pengamatan yaitu
Desa Babagan, Desa Karasgede, Desa Karaskepoh (Pancur) dan Desa Tuyuhan.

\section{Metode Penentuan Data}

Dalam penelitian ini pengumpulan data dilakukan dengan penelitian lapangan melalui :

1. Pengambilan data primer (karakter fisik yang mempengaruhi karakter visual dan memetakanya dengan gambar foto atau sketsa).

2. Pengamatan dengan melakukan observasi dan wawancara.

\section{Teknik Analisa Data}

1. Menyiapkan peta area penelitian yaitu peta jaringan jalan dan bangunan di desa wisata batik Lasem.

2. Mengobservasi komponen-komponen karakter fisik yang membentuk karakter visual kawasan, kemudian memilih key area yang akan diteliti karakter visualnya.

3. Mempetakan key area yang dipilih dengan cara merekam dengan foto dan sketsa serta melakukan pengukuran dimensi fisik dari area tersebut. Selanjutnya merekam aktivitas yang berlangsung di kawasan.

4. Menganalisa karakter visual secara fisik (karakter bangunan dan lingkungan), serta integritas kedua karakter tersebut.

\section{Tinjauan Pustaka}

\section{Karakter Visual}

Pengertian karakter visual dapat ditelusuri dari arti kata karakter dan visual. Pengertian karakter menurut Poerwadarminta (1972), berarti aksen, logat, ciri khas. Sedangkan pengertian visual itu berdasarkan penglihatan, dapat dilihat, kelihatan. Menurut Smardon tanda-tanda visual adalah ciri-ciri utama secara fisik dapat dilihat, yang dapat memberikan atribut pada sumber visual dalam suatu sistem visual, sehingga sistem visual tersebut mempunyai kualitas tertentu.

Definisi karakter Visual menurut para pakar adalah sebagai berikut : Karakter visual suatu kawasan ditunjukkan oleh adanya kualitas fisik yang terbentuk oleh hubungan atau interrelasi antar elemen visual pada suatu lansekap kota (Smardon,1986). Atribut yang dapat menunjukkan karakter visual ini meliputi:

1. Dominasi, ditimbulkan oleh satu atau dua elemen yang sangat kontras, yang secara visual sangat menonjol. 
2. Keragaman (diversity), adalah tingkat keragaman visual.

3. Kontinuitas (continuity), adalah merupakan suatu kesinambungan visual.

4. Kepaduan (intacnes), adalah integritas dari tatanan pada lansekap alam maupun buatan manusia, dan bebas dari gangguan visual.

5. Kesatuan (unity), adalah harmoni kesatuan secara menyeluruh yang mengacu pada kecocokan atau kesesuaian antar elemen visual.

6. Sequens (sequence), adalah tatanan unitunit visual yang berurutan menuju pada suatu arah tertentu (menuju pada suatu hirarki).

7. Keunikan (uniqueness), adalah suatu kondisi atau karakter visual yang tidak dijumpai pada lingkungan lain.

8. Keindahan (vividness), adalah penampilan y ang secara visual mengesankan dibentuk oleh adanya elemen atau unit visual yang secara visual menonjol dan menarik.

\section{Faktor Pembentuk Karakter Visual}

Menurut Shirvani (1985) faktor pembentuk karakter visual meliputi :

1. Ketinggian Bangunan

2. Kepejalan Bangunan

3. Cahaya Matahari dan angin

Ada lima kategori elemen menurut Lynch (1969) yang dapat dipergunakan orang untuk menstrukturkan gambaran kognisi dari sejumlah tempat, yaitu landmark, nodes, edges, path dan district.

\section{Faktor Estetika Visual}

Faktor-faktor estetika pada urban design menurut Moughtin (1995) adalah terdiri dari 7 faktor :

1. Keterpaduan (unity)

2. Proporsi

3. Skala (scale)

4. Keseimbangan (balance)

5. Irama (rhythm)

6. Warna (colour)

7. Serial Vision (urutan-urutan pandangan)

\section{Teori Place}

Berbicara place tidak akan lepas dari space, karena baik space dan place saling berkaitan. Place theory merupakan perpaduan antara manusia, budaya, sejarah, serta lingkungan alam. Inti teori place didasarkan pada pemahaman bahwa place adalah perubahan dari bentuk fisik dari space setelah terintegrasi dengan karakter budaya dan manusia. Juga mempunyai pemahaman karakteristik nilai-nilai social budaya, menambahkan komponen kebutuhan manusia, konteks budaya, sejarah serta alam.

Setiap place adalah unik memuat karakter tertentu dari lingkungannya. Karakter ini terdiri dari benda padat yang mengandung material, bentuk, warna, tekstur serta nilainilai kultur yang tidak nampak. Lebih jelasnya, dalam teori place menekankan bahwa integrasi kota tidak hanya terletak pada konfigurasi fisik ruang dengan masyarakat yang merupakan suatu tujuan yang paling utama karena pada hakekatnya urban design adalah bertujuan memberi wadah kehidupan yang lebih baik bagi penggunaan ruang kota secara privat atau publik.

\section{Karakter Batik Lasem}

Batik Lasem mempunyai ciri khas yang berbeda dari batik-batik dari daerah lain seperti batik Solo, Yogya, Pekalongan, dan lain sebagainya. Batik Lasem karena dirintis dan dikembangkan oleh masyarakat keturunan Cina, maka motif dan warnanya dipengaruhi oleh motif dan warna yang khas budaya Cina, yaitu merah, putih, biru, dan hijau. Sebenarnya ada beberapa daerah yang memproduksi batik yang dipengaruhi oleh motif dan warna-warna khas Cina, seperti batik Pekalongan, batik Cirebon, dan lain sebagainya, namun batikbatik dari daerah-daerah tersebut berbeda dari batik Lasem. Ciri khas batik Lasem adalah warna merah yang menyerupai warna darah.

Warna merah khas batik Lasem disebut dengan abang getih pithik (merah darah ayam). Warna abang getih pithik ini dihasilkan dari pewarna alam yaitu dari warna akar pohon mengkudu (pace). Warna merah yang khas ini telah menarik minat pembatik dari daerahdaerah lain untuk melakukan proses pewarnaan atau pencelupan untuk warna tersebut di Lasem. Bahkan ada batik yang terkenal dengan Batik Tiga Negeri, yang proses pewarnaannya dilakukan di tiga daerah yaitu untuk proses pewarnaan sogan dilakukan di Solo, proses pewarnaan merah di Lasem dan 
proses pewarnaan biru dilakukan di Pekalongan.

\section{Landasan Teori}

Untuk mendapatkan karakter visual pada suatu kawasan pertama-tama harus memahami komponen-komponen karakter fisik (fenomena fisik) yang membentuk dan mempengaruhi kondisi visual dari kawasan tersebut yang meliputi :

1. Karakter bangunan

2. Karakter lingkungan

3. Integrasi karakter bangunan dan lingkungan

\section{Parameter}

Parameter yang digunakan dalam penelitian karakter bangunan adalah karakter fisik bangunan yang berkaitan dengan bahasan tentang bentuk dan tatanan massa bangunan (Shirvani, 1985), yang pada dasarnya membahas mengenai penampilan bangunan berupa: skala ketinggian bangunan, façade bangunan, langgam/gaya, material, tekstur dan warna.

Parameter yang digunakan dalam penelitian karakter lingkungan adalah menggunakan parameter citra kota dari Lynch (1969) yaitu path, edge, node dan landmark.

Parameter yang digunakan dalam penelitian karakter bangunan dan lingkungan adalah parameter yang berhubungan dengan optic atau pemandangan kota yaitu view dan vista (Cullen,1961).

\section{HASIL DAN PEMBAHASAN}

Karakter Fisik Area Desa Wisata Batik Lasem dibagi menjadi 4 segmen yaitu:

\section{Desa Babagan}

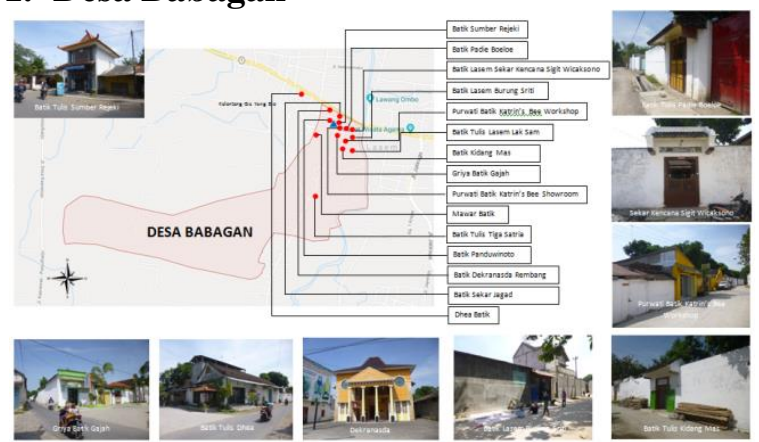

Gambar 1. Peta sebaran showroom Batik Tulis di Desa Babagan

Masa bangunan yang ada di Desa Babagan cenderung bergaya arsitektur China, dapat dilihat dari beberapa fasade bangunan yang hanya terlihat pada dinding-dinding setinggi 3-
4 meter. Masing-masing rumah ditandai oleh pintu yang diatapi semacam gapura. Pada pagi dan siang hari aktivitas berjualan dan produksi membatik dilakukan didalam rumah. Sehingga jalan pada area ini tidak terlalu nampak ramai, bahkan cenderung agak sepi. Lebar jalan dan potongan jalan sekitar 5 meter. Untuk skala ketinggian bangunan pada potongan $\mathrm{A}-\mathrm{A} ; \mathrm{D}=$ $5 \mathrm{~m}, \mathrm{H}=3,5 \mathrm{~m}$, jadi $\mathrm{D}=1,42 \mathrm{H}$ sehingga rata-rata skala ketinggian bangunan pada area ini $\mathrm{D} / \mathrm{H}=1$, hal ini menimbulkan kesan ruang terasa seimbang dalam perbandingan jarak dan ketinggian bangunan.

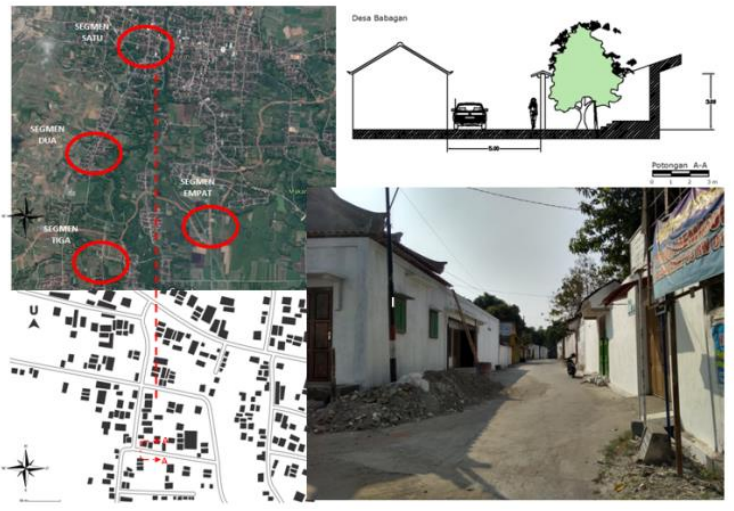

Gambar 2. Situasi dan Potongan Lingkungan salah satu ruas jalan Desa Babagan

\section{Desa Karasgede}

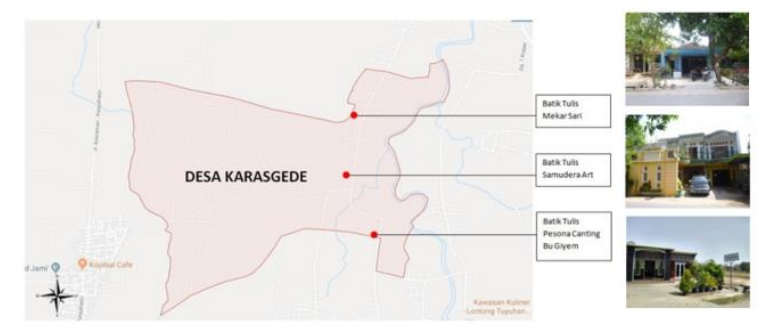

Gambar 3. Peta sebaran showroom Batik Tulis di Desa Karasgede

Masa bangunan yang ada di desa wisata Karasgede ini terbilang cukup modern, dapat dilihat dari penampakan wajah bangunannya yang sudah meninggalkan bentuk-bentuk tradisional Jawa. Didukung juga dengan penggunaan material bangunan seperti kaca, beton dan lain-lain sehingga memperkuat penampakan wajah bangunan lebih ke arah modern.

Aktivitas berjualan batik dan produksi batik di daerah Karasgede ini lebih banyak dilakukan di rumah. Showroom dan tempat produksi menjadi satu tempat. Jalan pada area ini tidak terlalu ramai dikarenakan masih 
terdapat jarak antar rumah yang cukup lebar. Berbeda dengan Babagan, untuk Karasgede ini sebagian penduduknya masih didapati memiliki mata pencaharian bercocok tanam. Lebar jalan dan potongan jalan sekitar 4 meter. Untuk skala ketinggian bangunan pada potongan $\mathrm{B}-\mathrm{B} ; \mathrm{D}=4 \mathrm{~m}, \mathrm{H}=3,5 \mathrm{~m}$, jadi $\mathrm{D}=1,1 \mathrm{H}$ sehingga rata-rata skala ketinggian bangunan pada area ini $\mathrm{D} / \mathrm{H}=1$, hal ini menimbulkan kesan ruang terasa seimbang dalam perbandingan jarak dan ketinggian bangunan.

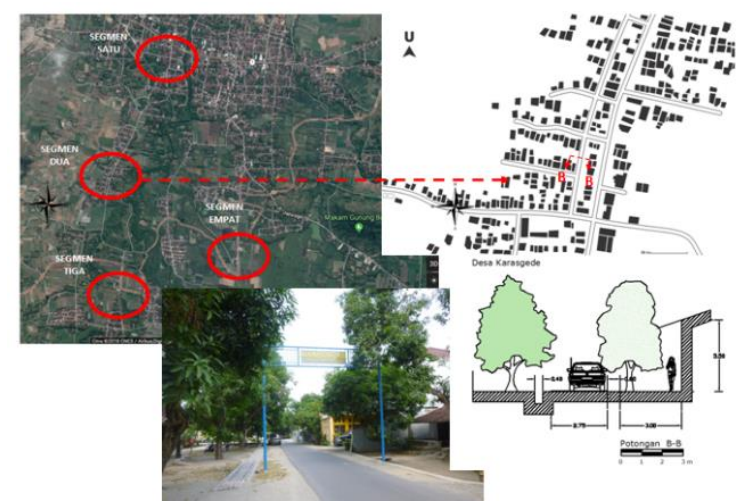

Gambar 4. Situasi dan Potongan Lingkungan salah satu ruas jalan Desa Karasgede

\section{Desa Karaskepoh}

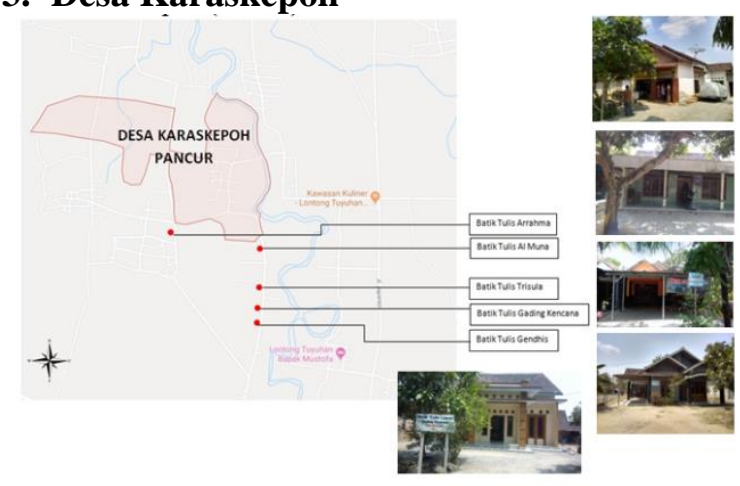

Gambar 5. Peta sebaran showroom Batik Tulis di Desa Karaskepoh

Di desa Karaskepoh Pancur ini juga yang ada tidak sepadat di desa wisata Babagan dan Karasgede. Untuk wajah bangunannya sebagian besar masih memiliki rumah tradisional, dapat dilihat dari penampakan wajah bangunannya yang masih menggunakan bentuk-bentuk tradisional Jawa. Didukung juga dengan penggunaan material bangunan seperti kayu, bambu, gedek dan atap genteng tanah liat. Untuk fasade yang ada di wilayah Desa Karskepoh sendiri lebih sebagian besar masih mengikuti bentukan asli atau cenderung ada sedikit perubahan pada materialnya. Dan sebagian lagi lebih memilih bentukan yang lebih modern. Hal ini nampak di Showroom Batik Tulis Gading Kencana. Aktivitas berjualan batik dan produksi berada pada satu lokasi. Jalan pada area wilayah Desa Karaskepoh ini terbilang tidak terlalu ramai. Aktivitas kendaraan yang melalui jalan ini tidak terlalu padat.

Lebar jalan dan potongan jalan sekitar 4 meter. Ditambah area kosong dan goronggorong dari pinggir jalan sampai pada bangunan rumah sekitar 4,8 meter. Untuk skala ketinggian bangunan pada potongan E-E; $\mathrm{D}=12,6 \mathrm{~m}, \mathrm{H}=3,5 \mathrm{~m}$, jadi $\mathrm{D}=3,6 \mathrm{H}$ sehingga rata-rata skala ketinggian bangunan pada area ini $\mathrm{D} / \mathrm{H}>1$, hal ini menimbulkan kesan ruang terasa agak besar. Sedangkan kecenderungan bangunan dilihat dalam hubungan dengan lingkungan.

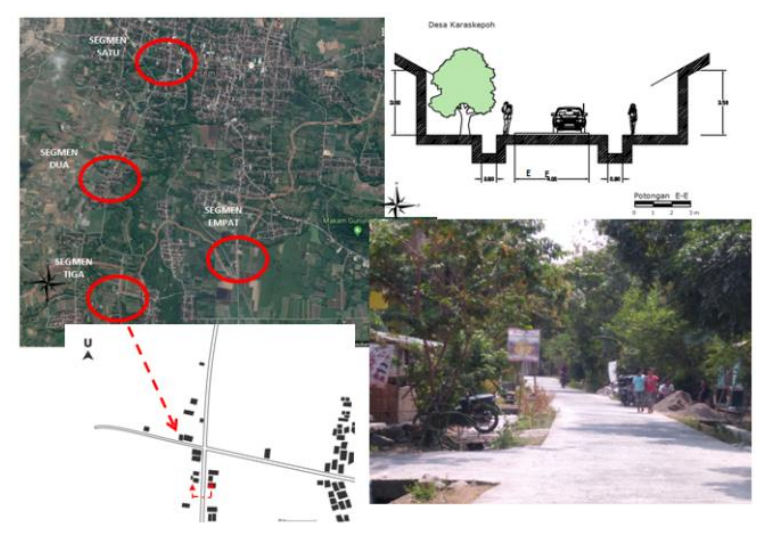

Gambar 6. Situasi dan Potongan Lingkungan salah satu ruas jalan Desa Karaskepoh

\section{Desa Tuyuhan}
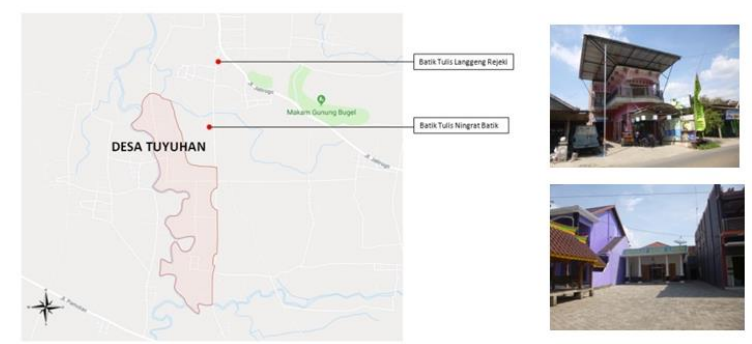

Gambar 7. Peta sebaran showroom Batik Tulis di Desa Tuyuhan

Di Desa Tuyuhan, masa bangunan yang ada tidak sepadat di desa wisata Babagan dan Karasgede. Untuk wajah bangunannya ini juga hampir sama dengan di Karasgede terbilang cukup modern, dapat dilihat dari penampakan 
wajah bangunannya yang sudah meninggalkan bentuk-bentuk tradisional Jawa. Pada showroom batik Tulis Ningrat tetap memberikan simbol atau ikon atap khas gaya China seperti yang ditemukan pada bentukan rumah-rumah yang ada di Desa Babagan.

Lebar jalan dan potongan jalan sekitar 5 meter. Ditambah halaman dari pinggir jalan sampai pada bangunan rumah sekitar 10 meter. Untuk skala ketinggian bangunan pada potongan $\mathrm{C}-\mathrm{C} ; \mathrm{D}=15 \mathrm{~m}, \mathrm{H}=3,5 \mathrm{~m}$, jadi $\mathrm{D}=4,2 \mathrm{H}$ sehingga rata-rata skala ketinggian bangunan pada area ini $\mathrm{D} / \mathrm{H}>4$, hal ini menimbulkan kesan ruang sudah terasa. Sedangkan kecenderungan bangunan hanya sebagai pembatas kedepan saja.

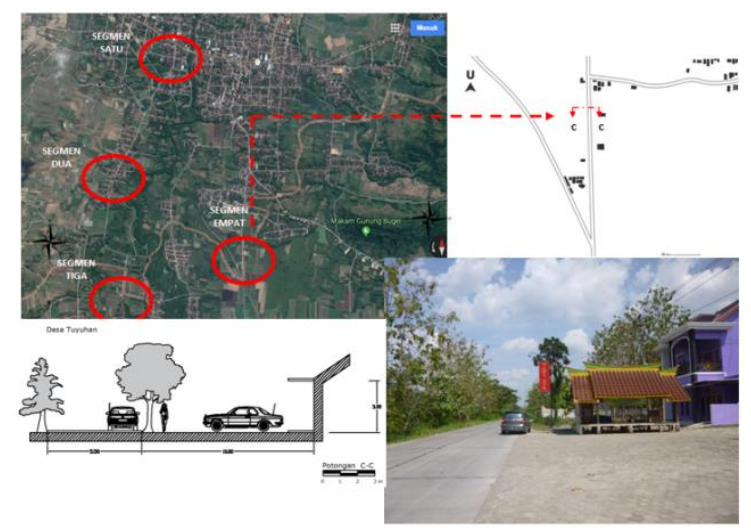

Gambar 8. Situasi dan Potongan Lingkungan salah satu ruas jalan Desa Tuyuhan

\section{Karakter Non Fisik Area Desa Wisata Batik Lasem}

1. Kebutuhan Dasar Manusia (Human Basic Need)

Pada dasarnya warga Tionghoa sebagian besar memenuhi kebutuhan hidupnya dengan cara berdagang. Dengan kedatangannya ini sebagian besar warga Tionghoa banyak membantu warga pribumi sekitar untuk dapat memahami cara membatik yang baik dan benar sampai mereka mampu memiliki usaha batik.

2. Struktur Kekerabatan (Family Structure) Dalam struktur kekerabatan pada warga Tionghoa keluarga memegang peranan penting dibandingkan kepentingan individu. Dimana pada pola perumahan masyarakat China, tempat tinggal bukan dipandang sebagai tempat utama untuk dihuni anggota keluarga secara individu tetapi lebih dianggap sebagai lambang persatuan dan status sosial bagi keluarga besar semarga baik yang masih hidup maupun yang sudah mati.

3. Interaksi Sosial (Social Intercourse) Interaksi sosial pada desa Karasgede, Karaskepoh dan Tuyuhan ini cenderung bagus, kekeluargaan antar warga pribumi cukup kental. Berbeda halnya dengan interaksi sosial di desa Babagan yang terlihat cukup tertutup. Hal tersebut dinilai dari pagar pembatas antar rumah yang tinggi.

\section{Kaitan Visual Antar Desa Wisata Batik}

Kaitan visual antar Desa Wisata Batik ditandai oleh beberapa faktor anatara lain yaitu: Landmark, adanya Pintu gerbang masuk dengan ornamen canting bisa dijadikan acuan untuk memasuki kawasan desa wisata batik tulis Lasem. Path, terdapat jalur atau jalan yang menghubungkan antara Desa wisata batik tulis yang ada di Babagan menuju Desa wisata yang ada di Karasgede, Karaskepoh dan Tuyuhan. Edges, nampak sungai Lasem sebagai edges yang membatasi wilayah Babagan dengan Karangturi. Nodes, didapati pada jalur jalan menuju desa Karasgede terdapat sedikit simpul persimpangan.

Pada jalan menuju desa wisata batik Karasgede pengunjung tidak terlalu bingung dengan adanya sedikit persimpangan ini.View merupakan pemandangan yang diamati dari suatu tempat yang dapat memberikan image tertentu. Pada desa wisata batik Lasem ini view yang tampak sangat kental dengan pemukiman China dengan pagar-pagar yang tinggi dan tertutup terutama pada Desa Babagan.

\section{SIMPULAN}

1. Karakter Visual Lingkungan desa wisata batik tulis Lasem dibentuk dan dipengaruhi oleh komponen-komponen: karakter fisik sebagai komponen utama dan karakter non fisik sebagai komponen penunjang dengan memperhatikan sejarah perkembangan Kawasan Lasem.

2. Karakter Lingkungan Desa Wisata Batik Tulis Lasem adalah sebagai berikut :

a. Permukiman Warga Tionghoa

Karakter asli pemukiman China di Desa

Babagan sangat menonjol. Aktivitas perdagangan kurang berkembang dan 
sudah mulai ada pembongkaran untuk bangunan dengan tujuan meningkatkan penjualan batik tulis mereka.

b. Permukiman Warga Pribumi

Karakter asli pemukiman warga pribumi muncul di Desa Karasgede, Desa Karaskepoh dan Desa Tuyuhan. Akstivitas perdagangan berkembang pesat sehingga beberapa bangunan asli tradisional Jawa mengalami perubahan bentuk menjadi bangunan yang modern seiring dengan perkembangan pola laku batik tulis Lasem yang semakin meningkat.

\section{DAFTAR PUSTAKA}

Cullen, G., 1961, The Consice of Townscape, Van Nostrand Reinhold Company, New York.

Lynch, K., 1969, The Image Of The City, The MIT Press, Cambridge

Moughtin, C., 1995, Urban Design: Ornament and Decoration, Butterword, Oxford.

Muhadjir, N., 1996, Metodologi Penelitian Kualitatif, Rake Sarasin, Yogyakarta.

Poerwadarminta, 1972, Kamus Lengkap, Hasta, Jakarta.

Shirvani, H., 1985. The Urban Design Process. Melbourne: Van Nostrand Reinhold Company.

Smardon, R., 1986, Foundation for Visual Project Analysis, John Wiley \& Son, New York. 